\title{
Melibea, Melíboia
}

\author{
Henk de Vries
}

Cejador copiaba en sus notas lo que Menéndez y Pelayo había escrito sobre los nombres de los personajes de la (Tragi-) Comedia de Calisto y Melibea: Plauto y Terencio tenían sus Pármenos, Sosias, Critos, Thrasos y Chremes; Sempronio y Lucrecia son nombres romanos; para Alisa, Tristán y Celestina alegaba antecedentes literarios. Estos dos críticos tomaban muy en serio todo lo reunido por Covarrubias, no solo la interpretación del nombre de la trágica protagonista como 'la de voz melosa', sino también la derivación, por cierto muy desacertada, del nombre de la alcahueta del adjetivo latino scelestus 'criminal'.

Acaso la idea que expresó don Marcelino, de que «el Melibeo de las églogas virgilianas pasó a nuestra tragicomedia cambiando el sexo", provocara a Cejador a añadir que Melíboia es población de Tesalia que Homero menciona en la Ilíada (II, 717). El pasaje, que forma parte del largo catálogo de las naves aqueas, dice como sigue -y cito por la admirable traducción de Alfonso Reyes: ${ }^{1}$

De Metone y Taumacia, también de Melibea

y la Olizón fragosa, siete naves arrea

Filoctetes, arquero de pro, con sus cincuenta remeros cada una y flecheros de cuenta.

Mas él quedó penando en la isla divina

de Lemnos, donde presa de la hidra dañina

fue abandonado. Pero no ha de tardar el día

en que la gente aquea se acuerde de su rey.

En tanto, aunque lo añoran, no navegan sin ley, porque el hijo de Rena y bastardo de Oileo, el vencedor de plazas Medonte es quien los guía, supliéndolo en el mando y el militar empleo. ${ }^{2}$

1. Obras completas de Alfonso Reyes, XIX: Los poemas homéricos. La Iliada. La afición de Grecia. [Al cuidado de Ernesto Mejía Sánchez y Saúl Jiménez Crispín. Estudio preliminar de Ernesto Mejía Sánchez. Ilustraciones de Elvira Gascón.] México: Fondo de Cultura Económica, 1968.

2. Pág. 137. Corrijo el número de las naves. No he visto la primera edición, de 1951. Lo que trae el texto de las Obras completas, veinte, es error no atribuible al traductor, el cual observa 
Filoctetes, rey de Melíboia y amigo de Héracles, heredó el arco y las flechas del héroe cuando éste, emponzoñado por la sangre de Neso, decidió morir en una hoguera que él mismo erigió. Durante el viaje rumbo a Troya, una mordedura de serpiente le causó una llaga supurante muy dolorosa y tan hedionda que los aqueos, por consejo de Odiseo, le abandonaron en la isla de Lemnos. Cuando después de muchos años Odiseo hizo preso a un hijo de Príamo, Héleno, que era vidente, éste reveló a los aqueos que Troya sólo sería vencida por el arco de Héracles. Sófocles desarrolla en su Filoctetes el tema de la expedición de Odiseo a Lemnos a recoger al arquero infalible. "Solo Filoctetes me superó en la puntería del arco", dirá Odiseo (Odisea viII, 219). Llegado a Troya y curado por el médico Macaón, Filoctetes hirió mortalmente a Paris y así apresuró el fin de la guerra.

En la Odisea (III, 190) Néstor, en un discurso que dirige a Telémaco, menciona a Filoctetes entre los guerreros griegos que regresaron sanos y salvos a su patria. Dice una tradición que Filoctetes, al encontrar a Melíboia insurreccionada, volvió enseguida a hacerse a la vela en busca de nueva patria. Y en la Eneida Héleno pone a Eneas en guardia contra tres caudillos griegos que colonizaron la costa de la Italia meridional, entre ellos el dux Meliboeus Filoctetes, fundador de la ciudad de Petalia o Petelia - la Strongoli de hoy, a la cual, por tanto, podríamos apodar la Nueva Melibea. ${ }^{3}$

Es evidente que casi todos los personajes de la (Tragi-) Comedia llevan nombres significativos. ${ }^{4}$ También es cierto que algunos de estos nombres

correctamente en nota (pág. 298): «Son 1.186 barcos aqueos,» y el número erróneo de los barcos de Filoctetes es la única discrepancia con los números del original griego.

3. «... hic illa ducis Meliboei / parva Philoctetae subnixa Petelia muro.» Eneida III,401-2.

4. He ido apuntando mis ideas sobre el fondo de crítica social encubierta de la Celestina desde hace treinta años. Para los nombres remito a tres artículos y al estudio que acompaña mi traducción neerlandesa de la Celestina: "La Celestina', sátira encubierta: el acróstico es una cifra», BRAE 54 (1974) 123-152; sobre los nombres, págs. 129-130; "Sobre el mensaje secreto de 'Calysto y Melybea'”, en: La Celestina y su contorno social. Actas del I Congreso Internacional sobre 'La Celestina', ed. M. Criado de Val, Barcelona 1977, 135-151; sobre los nombres, págs. 139148; «'Libro, en mi opinión, divi-': la 'Comedia' y el acto primero», en: Arcadia. Estudios y textos dedicados a Francisco López Estrada 1, Dicenda. Cuadernos de filología hispánica 6, «1987», Madrid [1990], 235-254; sobre los nombres, págs. 249 nota 5 y 252-54; en págs 250-51, autocrítica de trabajos anteriores; págs 250 y 254, la pauta que he seguido desde entonces, de distinguir rigurosamente entre la Comedia original y las versiones alargadas. Sección 'Namen' (págs 314-20) de 'Verkenning van een labyrint' ('Exploración de un laberinto', págs 293-350) en: Komediespel van Knisters en Goziedemij. [Comedia de Calisto y Melibea]. Een eeuwwendentoneel in drie dagen en een ochtendschemer, algemeen bekend als 'La Celestina', 1500. Toegeschreven aan Fernando de Rojas en anderen; gevolgd door de tussenvoegsels van de verlengde versies. Vertaald en in het jaar 2000 toegelicht door Henk de Vries. Athenaeum - Polak \& Van Gennep, Amsterdam 2001.

Precisé mis ideas sobre la Comedia de dieciséis actos en «Sobre estructura y autoría de la Comedia de Calisto y Melibea», en Actas del v Congreso de la AISO, Münster 1999, Madrid/Frankfurt 2001, págs 1350-60. 
tienen un significado irónico, antifrástico. ${ }^{5}$ El autor de la Comedia - no he creído nunca en la existencia de un "antiguo autor» que no fuese el mismo que "acabó» la obra6 - aclaró en el texto dramático el significado de algunos nombres. En las palabras que Calisto dirige a Sempronio (acto II): "...llama a Pármeno, quedará conmigo", el autor recuerda a sus lectores que el nombre deriva del verbo griego paramenoo 'quedarse con alguien, seguir acompañándolo' y 'seguir viviendo' — como había escrito ya Donato que Parmeno equivale a 'manens et aditans domino' y 'fidelis servus'. El nombre de Pármeno es, pues, a todas luces irónico, así como el de Sempronio, que, junto al de Pármeno, casi inevitablemente se asocia con semper 'siempre'?

El nombre de la trágica protagonista no es irónico. Desde las primeras palabras de la Comedia — «En esto veo, Melibea...»-viene asociado, en prosa y en verso, con el verbo ver; y ella misma aclara su nombre poco antes de morir: "Tú, Señor, que de mi habla eres testigo, ves mi poco poder, ves quán cativa tengo mi libertad...» Como escribí ya en 1974, lo que expresa el nombre de la hija de Pleberio es una fórmula de juramento: mi Dios me vea, Dios me sea testigo. Aquellos españoles que habían sido forzados a abandonar la religión de los padres no dejarían pasar por alto, en estas palabras de Melibea, "lo que hacía más al caso y utilidad suya» (como lo expresa el prologuista de «1502»).

Hay en los nombres tanto de Calisto como de Melibea un aspecto que parece irónico y en el fondo no lo es: el cambio de sexo que señalaba

5. Paolo Cherchi busca en la Tragicomedia un sistema de onomástica regido por la antífrasis, pero tiene que reconocer que algunos nombres carecen de fondo irónico ("Onomástica celestinesca y la tragedia del saber inútil», en: Rafael Beltrán y José Luis Canet, eds., Cinco siglos de 'Celestina', València 1997, págs 77-90). Algunas conjeturas suyas coinciden con las que propuse en mis artículos de 1974 y 1977, que al parecer no conoce Cherchi.

6. La idea de que el mismo Rojas pudo escribir el acto primero años antes de decidirse a terminar la Comedia había sido propuesta en 1957 por J.E. Gillet y por P. Bohigas, éste apoyado por O.T. Green en 1960, según se ve en la reseña (1963) que escribió Herriott del libro de Deyermond sobre The Petrarchan Sources of 'La Celestina' (1961). Sobre las diferencias entre el acto I y el resto de la (Tragi-) Comedia había escrito Deyermond: "They reflect either the work of two authors or the work of one man writing at different times, having undergone a powerful literary influence in the interval.» En el apéndice A de The Art of 'La Celestina' (1956), Stephen Gilman había escrito: "Act I could have been a first sketch of La Celestina written when Rojas was a very young man and completed as the Comedia a few years later. Certainly such a hypothesis would explain most of the evidence available.» Emilio de Miguel Martínez merece admiración por la paciencia con la que explica que los mismos argumentos que algunos alegan en favor de una autoría dual abogan en favor de un autor único en cuanto estamos dispuestos a aceptar a éste a manera de hipótesis. Anunció el tema de su libro La Celestina de Rojas, Madrid 1996, en un artículo, "Rojas y el acto I de La Celestina», en Insula 497 (abril de 1988), 19-20.

7. Me parece probable que Rojas tomara la idea de dos nombres emparentados que predicen lo contrario de lo que va a suceder de Petrarca, quien da a los dos hijos cuya muerte predijo la madre Adelecta los nombres Eternio y Albricio. (Calisto a Celestina, Acto vI: "Qué más hazía aquella tusca Adeleta» etc.) 
Menéndez y Pelayo para ella se aplica también a él. Calisto, una ninfa del séquito de Artemis, fue amada de Zeus y le parió a Arcas; y para guardar a ella y al hijo de la ira de Hera el soberano dios los colocó en el cielo como las dos Osas, Mayor y Menor. Calisto lleva nombre de ninfa y el de Melibea se deriva del de un varón. No del pastor de las églogas, como se le ocurrió a don Marcelino, sino del dux Meliboeus de la Eneida. El cambio de sexo habrá sido para los lectores coetáneos un indicio del fondo alegórico de la obra; les ayudaría a comprender que las diatribas de Sempronio contra las mujeres (acto I) son una chifla, paródica y metafórica, de las invectivas estereotipadas dirigidas en su tiempo, y en todos los tiempos, contra los judíos.

Pero si el nombre de Melibea se deriva del de un rey guerrero que apresuró la caída de Troya, ${ }^{8}$ por otra parte nos acordamos enseguida cómo Calisto compara a Melibea con una ciudad (acto vI): "Que las cibdades están con piedras cercadas (...); pero esta mi señora tiene el coraçón de azero (...) Pues poned escalas en su muro: unos ojos tiene con que echa saetas (...) el asiento tiene en parte que a media legua no le pueden poner cerco.»

Esta tirada de Calisto la provocó el proverbio que citó Celestina: «que en una hora no se ganó Çamora, pero no por esso desconfiaron los combatientes;» y a la queja del enamorado ella replica: "Calla, señor, que el buen atrevimiento de un solo hombre ganó a Troya.» La imagen de Melibea como ciudad inexpugnable está engastada entre dos reminiscencias de ciudades cercadas. Y los lectores más avisados del siglo XVI se acordarían del procedimiento contrario, de origen árabe, la personificación de una ciudad como 'novia' del señor que la asedia, relación amorosa que en literatura española se ha señalado entre Granada y el rey don Jan II, entre Valencia y el Cid. ${ }^{9}$

Me parece muy posible que el autor de la Comedia escogiera el nombre de Melibea no solo por sus propiedades fónicas, sino también por ser nombre de ciudad. La múltiple capacidad asociativa del nombre sería para sus lectores señal del fondo alegórico de la Comedia, en el cual la trágica protagonista representa a los forzados a apostatar. Nótese asimismo que la leyenda de Filoctetes no sólo se asocia con el sitio de Troya, sino que ofrece otros motivos también elaborados en la Celestina, como hoguera, mordedura de serpiente, armas, arco y flechas.

La población que hoy lleva el nombre de $\mathrm{M} \in \lambda \iota \beta$ oเa - que se transcribe Melívia y así se pronuncia- se encuentra a pocos Kms. de la costa del Mar Egeo, a 42 de Lárisa por la carretera y a unos 47 en línea recta del

8. No queriendo volver a explicar aquí lo de la cifra de Rojas, le dejo al lector iniciado la opción de aplicarla a 'Filoctetes' y 'Melibea' o a 'Fyloctetes' y 'Melybea'.

9. Henk de Vries, «'Nueve meses' (Cantar de Mio Cid, 1209)», La Corónica XII.1 (Fall 1983) 116-8. El romance 'Abenámar, Abenámar' puede verse, por ejemplo, en el libro de Colin Smith, Spanish Ballads, 1978, págs 125-7. 
monte Olimpo. El monte Ossa la separa del valle del Tempe. Con certeza no se encuentra en el sitio de la antigua Melíboia, sino que corresponde al que antes se conocía como Athánaton ('inmortal'). ${ }^{10}$ Livio $(36,13,6)$ menciona otra ciudad nombrada Melíboia, cerca de Trikka, la Tríkala de hoy, es decir, a más de cien Kms. al oeste de la nuestra; y Melíboia es también el nombre de una heroína equiparada con varias Chloris. ${ }^{11}$

Visité Melíboia en septiembre del 2000 (Véase Apéndice 1). Es un pueblo soñoliento que desde la falda oriental de una colina mira hacia el mar. Correos y Ayuntamiento ocupan sendos pisos de una casa de la calle principal. Tiene callejuelas laterales que le traen al viajero a la memoria palabras de la infatigable alcahueta: "De día me aviso por donde venga de noche.» Una rústica torre domina la plazuela central, desde donde se divisa el Mar Egeo. Capilla blanca, con iconos capaces de provocar al viajero a susurrar entre dientes: "Si Dios me diese en el cielo la silla sobre sus santos...» Detrás de la torre, una rancia casa con balcón. "Subamos, señor, al açotea alta, porque desde allí goze de la deleytosa vista de los navíos...» En lo alto de la torre, una campana. «No havrás, honrado padre, menester instrumentos para aplacar mi dolor, sino campanas para sepultar mi cuerpo.»

La deleitosa vista de los navíos. Por aquí se hicieron a la vela las siete naves que mandó Filoctetes. Por estas aguas navegaron las mil ciento ochenta y seis de los aqueos. Y a lo largo de esta costa, con rumbo a Salónica / Thessaloníki, otros navíos trajeron judíos expulsados de Sefarad, en busca de nueva patria, como Filoctetes, aunque en dirección opuesta.

Hoy como hace cinco siglos, a veces quisiéramos detener o desviar el curso de la historia. Podríamos ambicionar que un libro tenga el poder del pez eje-neis, detenedor de navíos. " $\mathrm{O}$ natural contienda digna de admiración: poder más un pequeño pece que un gran navío con toda la fuerça de los vientos!»

10. Griechenland. Lexikon der historischen Stätten. Von den Anfängen bis zur Gegenwart. Herausgegeben von Siegfried Lauffer. München: C.H. Beck, 1989. Págs 416-7, art. Meliboia, firmado Kr $=$ Dr. Herwig Kramolisch, Neckargemünd. El autor supone que la antigua Melíboia estaba a un kilómetro al noroeste de Skíti, es decir a unos cinco Kms. del mar, como la actual Melíboia, pero unos siete Kms. más al Sur.

11. Der Kleine Pauly: Lexikon der Antike, München 1979, s.v. Meliboia. 


\section{Apéndice 1}
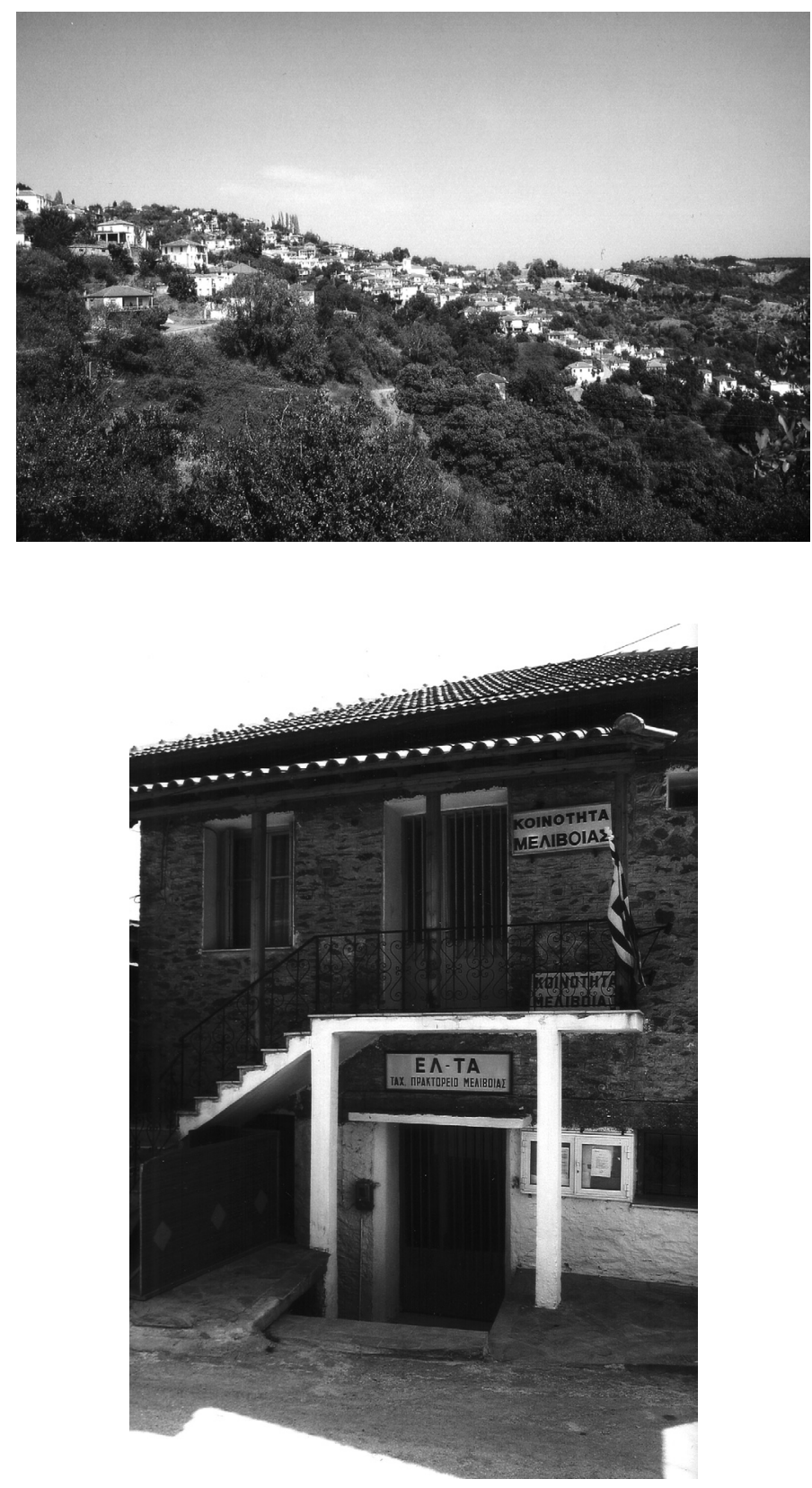

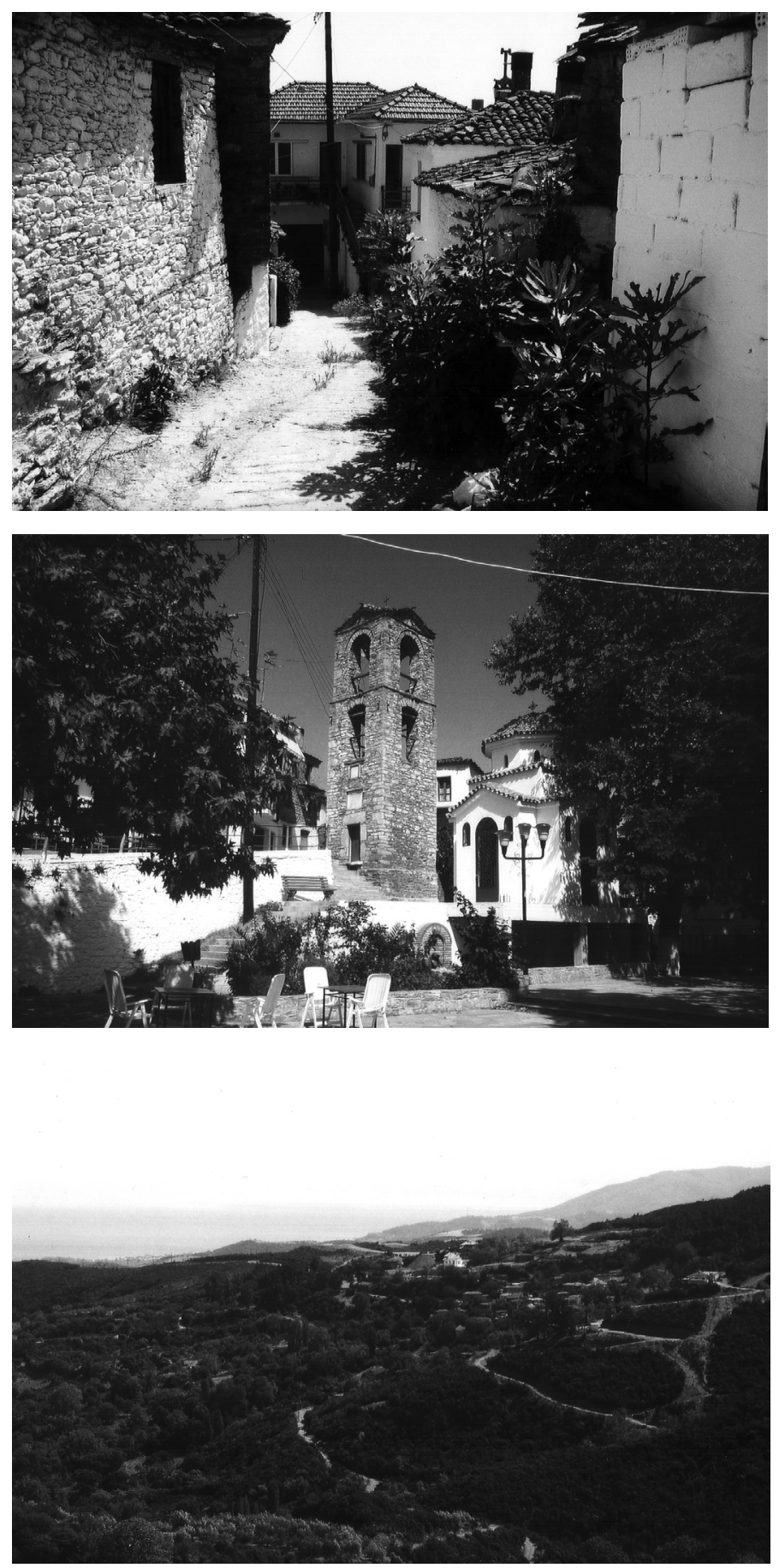

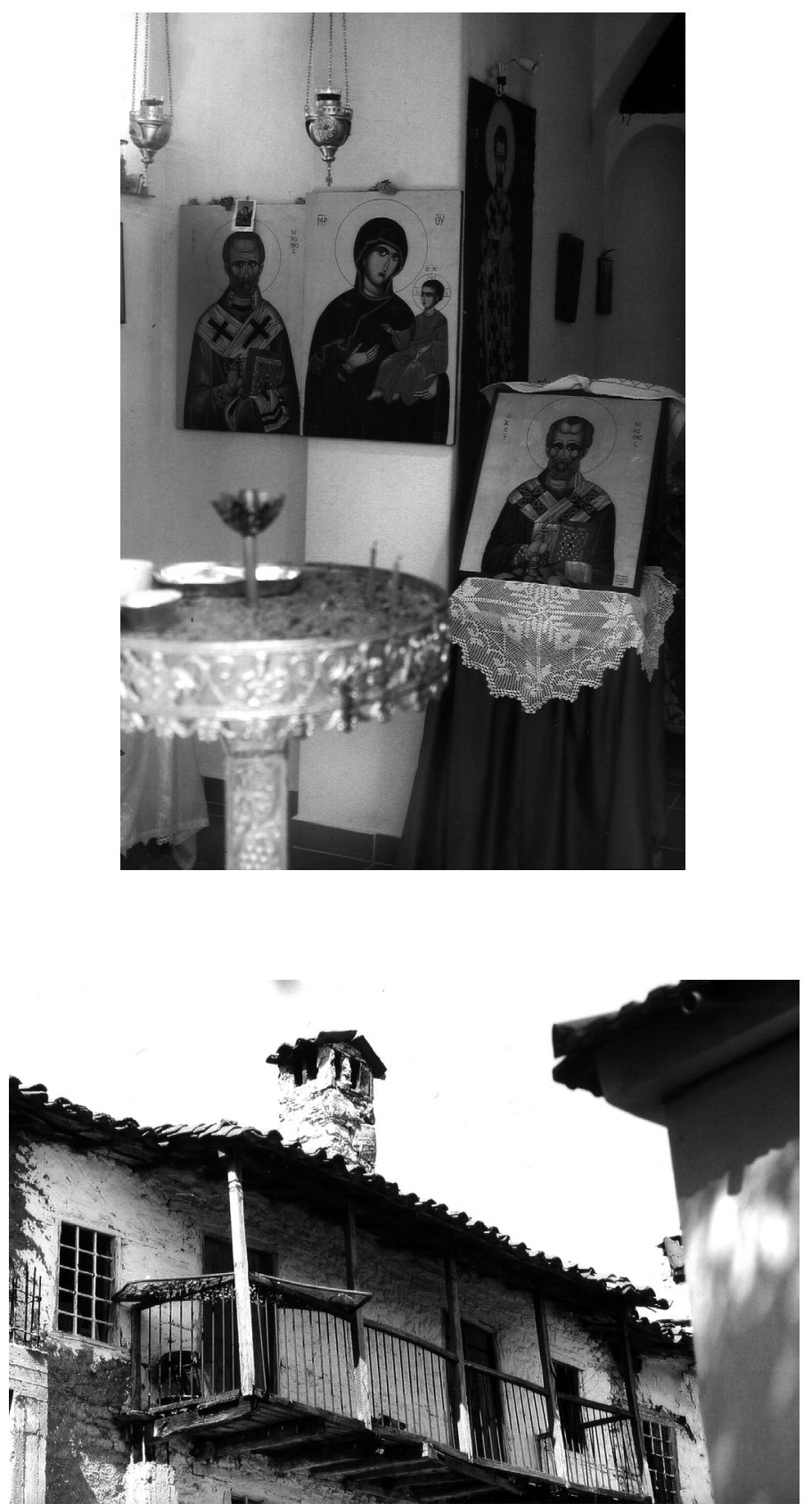


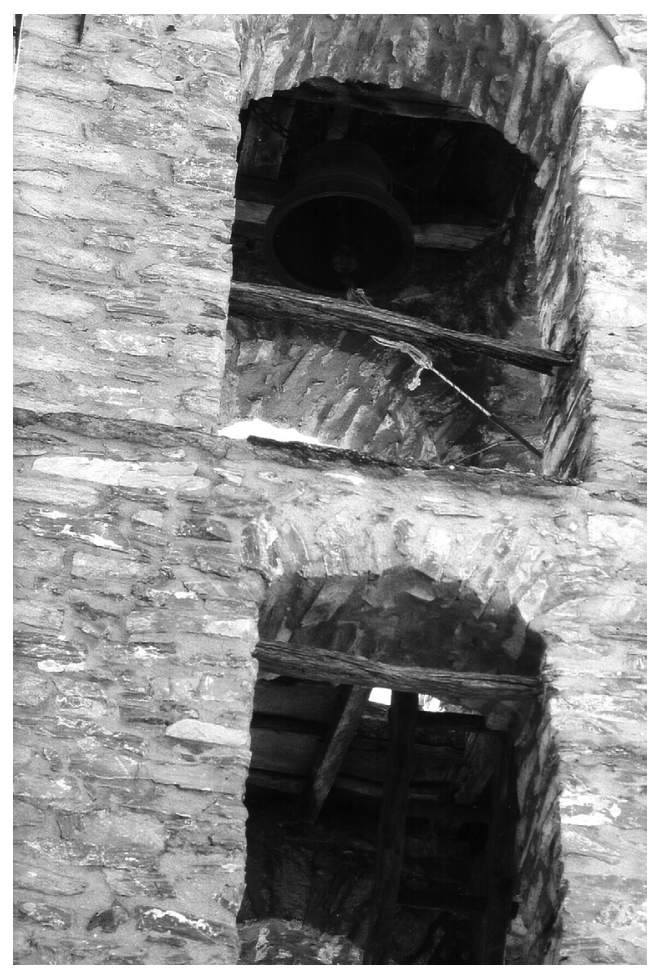


De Vries, Henk, «Melibea, Melíboia», Celestinesca 29 (2005), pp. 145-154.

\section{RESUMEN}

SE Comenta la polisemia de los nombres de Calisto y Melibea y sugiere que éste se tomó del de una población de Tesalia que menciona Homero

PALABRAS ClaVE: Celestina, Calisto y Melibea, onomástica, polisemia, Melibea (población de Tesalia), Filoctetes, Troya

\section{ABSTRACT}

Comments upon the polysemy of the names of Calisto and Melibea and suggests that the latter was taken from the name of a town in Thessaly mentioned by Homer.

KEY WORDS: Celestina, Calisto and Melibea, onomastics - polysemy - Melibea, town in Thessaly, Filoctetes, Troy

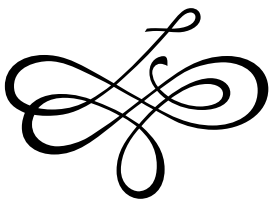

